\title{
Course teaching design of imaging electronics based on task driven:For electronic sphygmomanometer regulated power supply
}

\author{
Xingshan LI \\ Luohe medical college, Luohe, 462000, China \\ email: 604141388@qq.com
}

Keywords: task driven, imaging electronics, stabilized voltage supply

\begin{abstract}
Task driven teaching method applies to learning of action class knowledge and skills, especially for electronic technology application knowledge and learning skills. The implementation of the task driven teaching method mainly includes establishment situation, extraction task, task analysis, raise a question, explore, complete the task, communication, evaluation task and etc. In this paper, task driven teaching mode was applied in chapter of stabilized voltage supply. The ability of students' information technology, innovative spirit and practical ability were improved effectively, forming a new teacher-student relationship.
\end{abstract}

\section{Introduction}

The task driven, which is based on the teacher's help, closely revolves around a common task activity center. With the driving of strong problem motivation, through the active application of learning resources, to carry out autonomous exploration and interactive collaborative learning, and to guide students to produce a kind of learning practice in the same time to complete the task[1].Task driven is a teaching method based on Constructivism Teaching Theory. It requires the creation of the mission's goal and the teaching situation, which makes the students study in the exploration with real task. In this process, students will continue to get a sense of achievement, which can more greatly stimulate their desire to learn, and gradually form a virtuous cycle of the perception of mental activity, so as to cultivate the independent exploration, the courage to forge ahead of self-learning ability.

Task driven teaching should be based on the "task" to induce, strengthen and maintain achievement motivation of the learner. Achievement motivation is the real power system for students to learn and accomplish tasks. Task as a bridge for learning, what drive students to complete the task is neither the teacher nor the task, but the learner itself, which to further say that the learner's achievement motivation. Therefore, the task is not static and isolated, it should be the direction of the learners' achievement motivation, that is, the task is a process of evolution from the outside, which objective is the purpose of the achievement motivation. Task driven is a process that from task inner drive to motive drive. Self enhancement driven is that driven by self enhancement of internal drive as the core of the study[2]. The inner drive of self enhancement is the need for the individual to gain the appropriate status because of theirs ability to learn or work. The inner drive of self enhancement is different from that of cognition, which is not directly to the learning task itself, but rather to the achievement as the source of the status and self-esteem. Obviously, it is a kind of external motivation. In the teaching process of task driven, we can through the selection of expert learning, learning team leader's replacement, individual or group of work competition, etc.,which to stimulate students to improve the internal drive by material and spiritual rewards and other ways. Because these methods can make students experience the sense of honor, self-esteem, experience learning the success and failure.

On the other hand, the failure which Learning task is not complete or was not ideal is a threat to the self-esteem and it can also promote students in their studies to make long-term and arduous efforts. But you can't go to extremes, regulate the difficulty of the task reasonable, so as not to let the students suffer repeated failures and excessive anxiety in the process of the task - driven teaching, loss of self-esteem and self-confidence. Of course, excessive emphasis on self 
enhancement of the internal drive is not appropriate.If the motivation of students' learning is mainly focused on obtaining personal reputation, position, which will affect the social value of learning.The students will not produce the desire to continue and in-depth study.

The auxiliary drive is the study that affiliated drive as core power drive. The subsidiary internal drive is a kind of external motivation, which is expressed by a person in order to maintain the approval or recognition of the elderly such as parents, teachers, etc[3].For example,someone who was praised by the teachers and students because of the outstanding performance in the process of complete the task, so as to strive to learn to better complete the task. This motive of excitation have such two conditions, the first, students and the elderly are dependent on emotional. The elderly who respected by students is an example for students to follow long term. Therefore, the information technology teachers should pay attention to their own self-cultivation and image shaping in daily life and teaching. Become a teacher that can be trusted and respected in the eyes of the students.The second, students will get a kind of status such as the envy of other students, etc, which from elders endorse or approve[4]. Therefore, teachers should be good at finding and recognizing the advantages of students in process of the task driven teaching. Such as some students are creative and some have a strong ability to do it, while some students may have special skills in terms of team coordination, organization, etc. To the youth, the subsidiary of the internal driving force not only weakened, and began to turn to the same age partners. Approval from partners becomes a factor which can strong excitation affiliated drive. Teachers should cultivate the atmosphere among studentsis that mutual respect, mutual appreciation, mutual learning. In the harmonious relationship between teachers and students to grow.

\section{Contents and Steps of Instructional Design}

Firstly, situations creation. To create an environment that is relevant to the current learning content, leading the students to the task in this situations. Vivid situation can enrich the students' association and improve students' learning interest, produce the motivation to accomplish the task. To arouse knowledge experience in the existing cognitive structure of the students, and then adaptation and assimilation the new learning content by the experience of knowledge. Construct knowledge experience of existing, Develop the ability of knowledge construction.

Secondly, Put forward the task. Under the real situation that has been created, the real event that closely related to study content and representative as the main content of the study. Let the students experience the process when facing a real problem to analyze and solve problems. Through the solution of the problem actively and extensive activate the original knowledge experience of students. Construct a new knowledge structure, which provides an ideal platform for the connection and development of new and old knowledge.

Once again, autonomous learning and collaborative learning. Under the task driven teaching mode, teachers should focus on the students' learning ability, pay attention to develop students' independent learning ability rather than the teacher directly to demonstrate or explain how to solve the problem. Promote collaborative learning, encourage students to discuss issues, exchange ideas and experiences, and supplement and revise the solution to the current problem.

Finally, effect evaluation. The task should be evaluated in time after it completed,including self evaluation, mutual evaluation and teacher evaluation. Evaluation content mainly have two aspects.One is the program for solve the problem and the results evaluation, the second is the evaluation of learning ability of autonomous and cooperative learning. The purpose of the evaluation is to allow students to explore ideas, positive innovation. The positive and effective evaluation of the students learning enthusiasm, increase the learning interest, learning motivation.

\section{Teaching Design Considerations}

Firstly, moderately easy.

Teacher must be familiar with the teaching material When carries on the teaching design, and needs overall consideration. The design of the task inappropriate too large, the knowledge points 
and difficulties not too much, and pay attention to the relationship between the knowledge points. Oversize difficulty of the task and oversize knowledge will enable students to have emotional difficulties, which is not conducive to building up students' self-confidence and further learning. The simplicity and the formalization of the task will deviate from the original intention of the task, and can not effectively stimulate the enthusiasm of students learning. Some teachers regard the teaching objectives of teaching materials as the task directly. Students do not have to carry out autonomous learning or cooperative learning to construct a framework of knowledge, but find the answer in the book directly. The task design violates the original intention of the task in the task driven Teaching.This teaching method can not be regarded as a task driven teaching, not only will not be welcomed by the students, the opposite will cause students to be bored, it is impossible to achieve good teaching results.

Secondly, consider the characteristics and differences of students

There are some differences in the ability of students to accept the knowledge because of the influence of the living background and learning environment. Before task driven design ,the teacher should take into account the students' physiological stage, cognitive ability, interest, and other characteristics. For the new knowledge points of the task and some difficult operation, teachers should demonstrate and explain to facilitate learning task smoothly.

Thirdly, taking the students as the center

Teacher is the organizer,guide and facilitator in task driven teaching , students are the subject of learning.So we should be student-centered when design task, considering the reality of the students, don't walk away. Under the proper guidance and assistance of teachers and actively learning and creation, students can complete the knowledge, thinking, skills and the construction of the sense of emotion.

Task design principles

(1) Interest principle

Interest is the best teacher. The new and interesting task can attract the attention of students, so the teacher should pay more attention to the students' preferences and stimulate students' learning desire, so as to actively participate in and complete the task.

(2) Authenticity principle

The design of the task is to provide a natural, true or simulated situation to the learner.In this way to maximize the development of students' learning potential, to develop students' creative thinking, real learning to find problems, solve the problem.

(3) Operability principle

The design of the task can not only from the theory of optimization, but should take into account the students' learning characteristics, ability level and other factors, but also consider the school teaching level, the implementation of the media conditions and environment, the availability of resources, rather than the simple choice theory

\section{Create Situations and Determine Tasks}

Take chapter one DC circuit of Image Electronics Foundation for example, description how to design the teaching task. Mission design: Production of electronic blood pressure meter DC power supply.

(1). Analysis of teaching object and teaching content

Before, the students have mastered the concept of electric current, voltage, electric potential, and has ability of design some simple circuit, master the knowledge of some components, such as resistance, capacitance, inductance, fuse, wire, transformer, etc., and master a certain number of welding technology and the use of universal meter.

(2). Determine the teaching objectives

Total teaching target: According to the circuit principle diagram and the parameters of the components, a simple power supply is made. At the same time, the relevant theoretical knowledge is grasped, and the contents and requirements of the teaching program are completed.

Moderate target: Finish simple power supply according to the circuit diagram and components. 
Higher goal: Play a creative thinking, with the learned knowledge to improve the circuit, in order to save costs, reduce power consumption (power output current is from tens to hundreds of milliampere ).

Moral education target: Cultivate students' innovative consciousness and spirit of cooperation. The circuit is shown in Figure1.

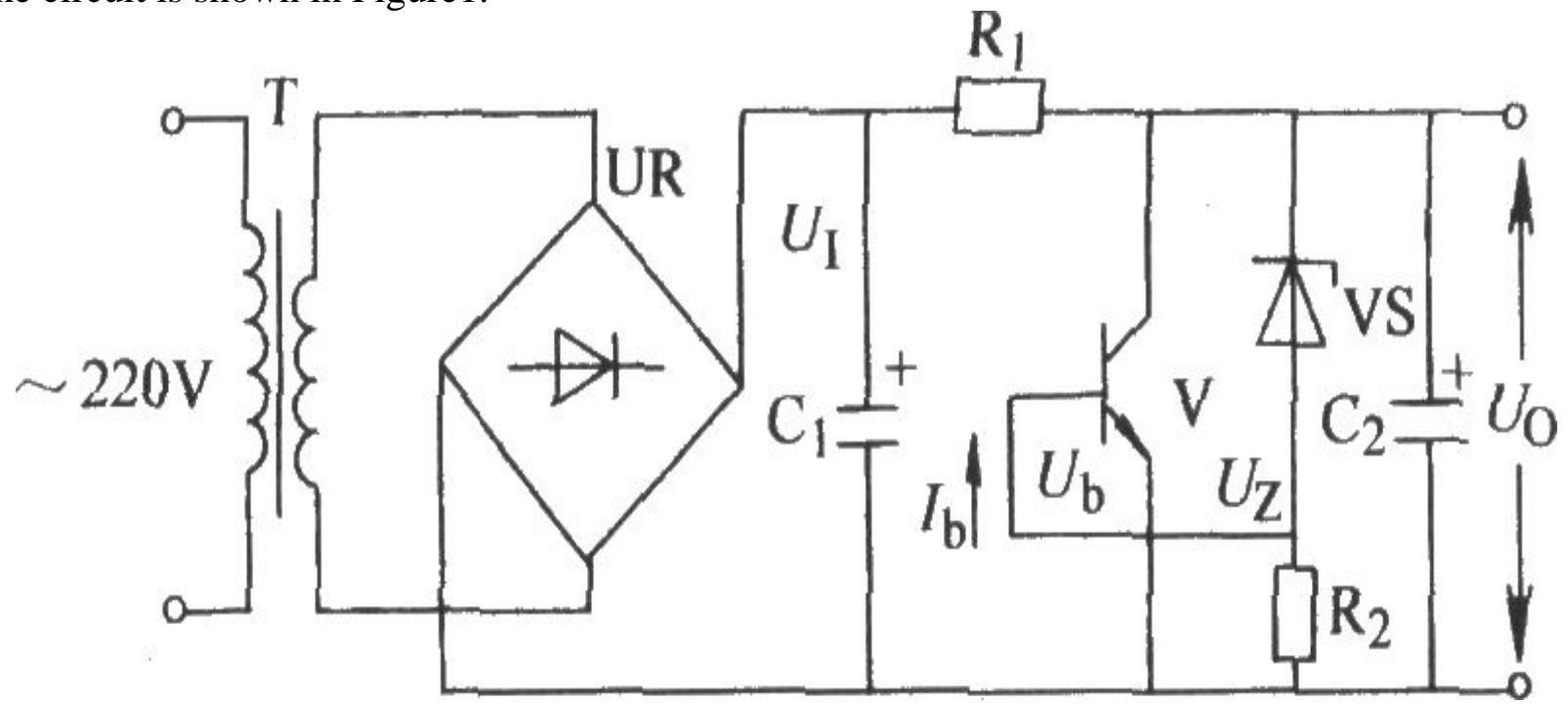

Fig.1. Power circuit diagram

(3).To refine the teaching objectives to the task

To segment the total target into small targets, such as knowledge and skills objective. To refine the small target to task.

a. knowledge objective

Task1: Familiar with the form of the diode device and the symbol of circuit diagram.

Task2: Familiar with the main characteristics and parameters of the diode.

Task3: Understand the basic composition and working principle of the rectifier circuit, simple engineering calculation.

Task4: Familiar with the basic form of capacitor filter and the selection principle of filter capacitor parameters.

Task5: Understanding the function and maintenance usage of the several special commonly used diode

b. Skill objective

Task1: Read simple power circuit diagram.

Task2: Design and installation circuit on the universal circuit board.

Task3: Using the multimeter to detect components.

Task4: Installation circuit according to the circuit design.

Task5: Power on after checked, and measure the output voltage value by the multimeter.

Task6: Observe secondary waveform, the waveform after the rectification and the filtered waveform of the transformer with an oscilloscope.

\section{Teaching Implementation Process}

Link1: Creating situations, causing attention, and put forward the task. The purpose of creating the task is to draw the task naturally and to stimulate the students' learning interest and motivation, and to deepen the understanding of the task. Clear the learning goals about accomplish the task.

Give full play to the characteristics of the curriculum practice in the teaching of Image Electronics Foundation, there are corresponding practical engineering application almost in every chapter of the teaching content, so it can be easily designed with the current task, as far as possible the real learning situation. In the design task, the teacher can create the situation by showing the work sample. In the sixth chapter rectifier and filter circuit, the creation of the task situation includes the Walkman power supply, mobile phone charger circuit, power amplifier, TV power 
supply circuit etc, then put forward the task of loading a rectifying filter circuit.

Link2: Common discussion, analysis tasks, and found the problem. After giving the above tasks, discuss with the students what problems need to be solved. For example: which is the device of the learned in this circuit? Which is not learned? What is the function of the circuit? what is the device ,s name which is not learned ? What constitutes? What characteristics? And so on. These problems can be brought out by the students themselves under the guidance of the teacher, and they also be offered by teachers according to actual situation. Students can not put all the problems of the task, they only have to practice before they can find and put forward for some of the problems, teachers should continue to guide students to contact the relevant knowledge of the past to find a solution to the problem.

Link3: Clear idea and put forward the key for problem. we must continue to guide students to put forward the method for the problems and help them to form the idea and plan to solve the problem.

Link4: Autonomous exploration, understanding the intention, the completion of the task. The students make a self evaluation according to the evaluation criteria (including the final work evaluation, method and process evaluation).

Link5: Check the results, find the shortage, sum up experience. Check the degree of task completion timely after the completion of the task, and make the relevant records, make feedback and summary timely about the degree of task completion to find out the existing problems and the place that need to improve.

\section{Conclusion}

The most basic characteristic of task driven teaching method is that task as the main line, the teacher as the dominant, the students as the main body". The passive teaching mode of teacher talk, students listen was be changed. The new learning mode of teaching by learning, students take the initiative to participate in, independent cooperation, explore innovative was be created. Through practice, the task driven method is to stimulate students' learning interest, cultivate students' ability to analyze problems, solve problems, improve students' autonomous learning and their ability to cooperate with others.

\section{Acknowledgement}

In this paper, the research was sponsored by the Health and Planning Committee of Henan Province (Project No. WJLX 2014081).

\section{Reference}

[1] Xu Tan-fei. The reform of electronic technology basic course by task driven teaching method[J] .Teaching vocational and technical education,2007,11:23-24

[2] Xu Xiu-ling. Computer class multi-dimensional integration with many ways of the students' autonomous learning[J]. Journal of Harbin vocational and technical college, 2014, (06):31-32

[3] Huang Jing. Analysis on Task-driven Teaching Method of Analog Electronics Technology Curriculum in Higher-vocational College [J]. JOURNAL OF HUNAN INDUSTRY POLYTECHNIC, 2014, 14(1):88-92

[4] Tong Xiao-wei. Task drive dynamic teaching method should be used in electronic technology course [J]. Mechanical and electrical technology, 2014, 6:146-149. 